\title{
Molecular and cellular markers for measurable residual disease in acute lymphoblastic leukemia
}

\author{
Gerardo Juárez-Avendaño" ${ }^{1 \#, ~ N e r e i d a ~ M e ́ n d e z-R a m i ́ r e z ~}{ }^{2 \#}$, Nuria C. Luna-Silva ${ }^{3}$, Victor A. Cruz-Hernández ${ }^{4}$ \\ David Gómez-Almaguer², Rosana Pelayo ${ }^{5 *}$, and Juan C. Balandrán ${ }^{1,6 *}$ \\ ${ }^{1}$ Laboratorio Juárez, Medicina de Laboratorio Clínico de Alta Especialidad, Biología Molecular e Investigación Clínica, Oaxaca de Juárez, Oaxaca, \\ Mexico; ${ }^{2}$ Hospital Universitario de la Universidad Autónoma de Nuevo León, Monterrey, Nuevo León, Mexico; ${ }^{3}$ Servicio de Hematología, Hospital \\ de la Niñez Oaxaqueña Doctor Guillermo Zárate Mijangos, Secretaría de Salud, Oaxaca de Juárez, Oaxaca, Mexico; ${ }^{4}$ Servicio de Hematología, \\ Hospital Dr. Aurelio Valdivieso, Secretaría de Salud, Oaxaca de Juárez, Oaxaca, Mexico; ${ }^{5}$ Centro de Investigación Biomédica de Oriente, Instituto \\ Mexicano del Seguro Social Delegación Puebla, Metepec, Puebla, Mexico; ${ }^{6}$ Ruth L. and David S. Gottesman Institute for Stem Cell and Regenerative \\ Medicine Research, Department of Cell Biology, Albert Einstein College of Medicine, New York, USA
}

\# Equal contribution

\begin{abstract}
Acute leukemia is the leading cause of death in children worldwide, particularly in developing countries where the growing number of cases with unfavorable prognosis and high risk of early relapse have positioned pediatric cancer as a priority. The late and imprecise diagnosis, malnutrition and unfavorable environmental conditions, and toxicity-associated therapy are some of the factors that compromise the success of the treatment and affect survival rates in vulnerable regions. An early and exhaustive classification of malignant neoplasms at the clinical debut and the proper follow-up of treatment's response constitute one of the most powerful prognostic factors. Remarkably, the ultrasensitive detection of residual and relapse clones that determine the minimal/measurable residual disease (MRD) has been a milestone in the comprehensive management of hematologic malignancies that favorably improve the complete remission cases. In this review, we discuss the scientific and technological advances applied to laboratory diagnosis in MRD determination: from the multiparametric immunophenotyping to next-generation sequencing and cytomics. As a result of multidisciplinary research in the main concentration oncology centers and laboratories, residual leukemia detection strategies that combine molecular analysis and cellular markers are recommended as the most valuable tools, making them the paradigm for stratification campaigns in vulnerable regions.
\end{abstract}

Keywords: Acute leukemia. Minimal/measurable residual disease. Flow cytometry. Polymerase chain reaction. Next-generation sequencing. Bone marrow.

\section{Marcadores celulares y moleculares para la enfermedad residual medible en la leucemia linfoblástica aguda}

\section{Resumen}

La leucemia aguda es la principal causa de muerte por enfermedad en la población infantil mundial, en particular en los países con economías en desarrollo, donde el creciente número de casos con pronóstico desfavorable y riesgo de recaídas tempranas ha posicionado a esta enfermedad como una prioridad de salud. El diagnóstico tardío y de baja precisión, la

\section{Correspondence:}

*Juan Carlos Balandrán

Date of reception: 13-06-2020 Date of acceptance: $20-07-2020$

E-mail: rosana.pelayo@imss.gob.mx DOI: 10.24875/BMHIM.20000155
Available online: 08-06-2021 Bol Med Hosp Infant Mex. 2021;78(3):159-170 www.bmhim.com 1665-1146/C 2020 Hospital Infantil de México Federico Gómez. Published by Permanyer. This is an open access article under the CC BY-NC-ND license (http://creativecommons.org/licenses/by-nc-nd/4.0/). 
ausencia de condiciones favorables de alimentación y entorno ambiental, así como la toxicidad asociada a la terapia, son algunos de los factores que condicionan el éxito del tratamiento y afectan las tasas de supervivencia en las regiones más vulnerables. La clasificación temprana y exhaustiva del tumor maligno en la presentación clínica y durante el seguimiento de respuesta al tratamiento es uno de los más poderosos factores pronósticos. En especial, la detección ultrasensible de clonas residuales y reemergentes que determinan la enfermedad residual mínima medible ha sido un hito en el manejo integral de las neoplasias hematológicas y ha impactado favorablemente en las cifras de remisión completa. En esta revisión se comentan los avances científicos y tecnológicos aplicados al diagnóstico de laboratorio y a la determinación de la enfermedad residual mínima: desde la inmunofenotipificación multiparamétrica hasta la secuenciación y la citómica de última generación. Como resultado de las investigaciones multidisciplinarias en los principales centros oncológicos de concentración y los laboratorios de clase mundial, las estrategias de detección de la leucemia residual que combinan análisis moleculares y marcadores celulares han sido recomendadas como las de mayor utilidad, por lo que son el paradigma para las campañas de estratificación en las regiones vulnerables.

Palabras clave: Leucemia aguda. Enfermedad mínima/medible residual. Citometría de flujo. Reacción en cadena de la polimerasa. Secuenciación masiva de siguiente generación. Médula ósea.

\section{Introduction}

Acute leukemia (AL) is the leading cause of death among children in Mexico and the rest of the world'. A new epidemiological health metric reflecting global tumor burden through the years lost due to disease or disability, and considering the life expectancy of each region, has placed Latin America as one of the regions where children lose more years of life due to leukemia? This type of neoplasm starts and progresses in the bone marrow, the tissue where hematopoiesis occurs, with the resulting imbalance in the formation of all blood cell types due to tumor growth ${ }^{3}$. Pediatric AL can occur in the lymphoid hematopoietic lineage, where B-cell precursor acute lymphoblastic leukemia (B-ALL) predominates, followed by the less frequent but very highrisk types T-cell precursor acute lymphoblastic leukemia (T-ALL) and acute myeloid leukemia (AML) of myeloid origin. Thanks to multi-institutional research programs, new conditions have been discovered recently, such as leukemia of ambiguous lineage, early T-cell precursor (ETP) leukemia, and Philadelphia chromosome-like (+) leukemia (Ph-like ALL). The knowledge of their complete identity results from the morphological analysis, karyotyping, immunophenotyping, chromosomal aberrations, transcriptomic analysis, and detection of mutations. Moreover, several clinical subgroups are now recognizable due to proteomic analysis of the surface of leukemic blasts and genomic studies that allow identifying the main differences between malignant clones and normal cell populations, revealing the high intraand inter-tumor heterogeneity that characterizes the pathobiology of this group of diseases ${ }^{4,5}$.

In this review, we will focus on the leading cellular and molecular markers of utility as a guide for the diagnosis and tracking of minimal/measurable residual disease (MRD) by the latest generation of multiparametric flow cytometry (more than eight colors) and by molecular techniques such as quantitative reverse transcriptase-polymerase chain reaction (RT-qPCR), digital PCR ( $\mathrm{PPCR}$ ), massive next-generation sequencing (NGS), as well as their prognostic value in clinical practice.

\section{Etiopathology of acute leukemia}

The uncontrolled proliferation of oligoclonal precursors (lymphoid or myeloid) is the common feature of these diseases. According to Lapidot et al., a cell subpopulation with stemness properties-cancer stem cells-in adult myeloid leukemia gives rise to and maintains the tumor load when transplanted into immunodeficient mice ${ }^{6}$. In contrast, le Visuer et al. reported that this does not appear to be the case in lymphoblastic leukemia, as stemness has no obvious phenotype ${ }^{7}$, but the existence of functional leukemia-initiating cells (LICs) has been extensively documented ${ }^{8,9}$. Although the etiology of the disease is still uncertain and variable, the existence of cells that acquire stemness properties to establish and maintain the disease is undoubted. In investigating the origin, the differentiation pathways involved, and clinical diagnosis, flow cytometry has been fundamental for determining the compromised lineage, identifying the aberrant expression of specific markers and tracing them throughout the disease.

Moreover, hematopoietic differentiation maps have been constructed through this tool and functional assays in vitro and in vivo, and new markers defining the function of progenitor cells in health and disease 
have been discovered. Thus, the compartment that enriches stem and progenitor cell populations is CD34 ${ }^{+}$CD 38 with the absence of mature lineage markers (Lin- $)^{3}$. The high frequency of $\mathrm{CD} 34^{+} \mathrm{CD} 38^{-}$cells at diagnosis has been associated with unfavorable outcomes and increased risk of relapse ${ }^{10}$. Under leukemic conditions, the normal progenitor compartment is numerically and functionally reduced, causing severe pancytopenia that clinically includes anemia, recurrent infections, and petechiae ${ }^{3,11}$. However, it is still a challenge to distinguish LICs from healthy hematopoietic stem cells phenotypically.

The competition between leukemic growth and normal cell development is under intense investigation. Among the most important findings is the tumor microenvironment and the remodeling of normal niches, that is, the sites where stem cells and progenitors inhabit ${ }^{12}$. It is suggested that leukemic clones produce cytokines, inflammatory factors ${ }^{13}$, and exosomal microvesicles ${ }^{14}$ containing micro RNAs and other products. These cell products drive the "conditioning" of normal niches and form hostile sites for normal clones favoring their escape or depletion while creating optimal niches for the proliferation of malignant clones ${ }^{12}$.

\section{Clinical diagnosis and laboratory evidence}

The oncologic treatment depends on the diagnosis, which should be comprehensive and include morphologic criteria, karyotyping, immunophenotyping, and the presence of confirmed genetic alterations. According to the World Health Organization (WHO), bone marrow aspirates should be used for leukemia diagnosis (Fig. 1). However, on certain occasions, the diagnosis can be implemented in peripheral blood as well ${ }^{15}$. Other criteria such as age, leukocyte count, evidence of infiltration to other organs, and early response to therapy help identify standard risk from high-risk patients.

The lineage suspicion is clarified by immunophenotyping, which should be initiated with a robust strategy to detect at least whether the affected lineage is lymphoid ( $\mathrm{B}$ or $\mathrm{T}$ ) or myeloid. If morphology yields more data on the myeloid precursor type, subsequent antibody combination or characterization panels should be based on these aspects to avoid performing lymphoid panels on clearly myeloid leukemia and vice versa ${ }^{16}$. The most commonly used antigens for the identification of B-cell lymphoid leukemia are CD19 or cytoplasmic CD79a (cyCD79a), while for T-lineage leukemia are surface CD3 (smCD3), cytoplasmic (cyCD3), and CD7, as well as the absence of antigens associated with the opposite lineage. On screening panels, myeloid leukemia is identified by the absence of the previously mentioned lymphoid antigens and the presence of myeloperoxidase (MPO) or some myeloid membrane antigens, including CD33, CD14, or CD13. In normal hematopoiesis, the common leukocyte antigen CD45 is acquired with maturation; thus, its low expression or absence is associated with more than $90 \%$ of AL cases and allows a clear identification of immature populations. The CD34 antigen, associated with stem cells and hematopoietic progenitors, is widely used in various diagnostic panels and denotes the level of (in) differentiation of leukemic blasts. In parallel, the search for translocations is usually performed routinely through commercial kits that can detect up to 28 leukemia-associated translocations: del1 (p32) (STIL-TAL1), t(1;11) (p32;q23) (MLL-EPS15), t(1;11) (q21;q23) (MLL-MLLT11), $\mathrm{t}(1 ; 19)$ (q23;p13) (TCF3-PBX1), t(3;5) (q25;q34) (NPM1MLF1), $t(3 ; 21) \quad(q 26 ; q 22)$ (RUNX1-MECOM), $t(4 ; 11)$ (q21;q23) (MLL-AFF1), $\mathrm{t}(5 ; 12) \quad$ (q33;p13) (ETV6PDGFRB), $\quad t(5 ; 17) \quad(q 35 ; q 21) \quad$ (NPM1-RARA), $\quad t(6 ; 9)$ (p23;q34) (DEK-NUP214), $\quad \mathrm{t}(6 ; 11) \quad$ (q27;q23) (MLLMLLT4), t(8;21) (q22;q22) (RUNX1-RUNX1T1), t(9;9) (q34;q34) (SET-NUP214), $\mathrm{t}(9 ; 11) \quad(\mathrm{p} 22 ; \mathrm{q} 23) \quad$ (MLLMLLT3), t(9;12) (q34;p13) (ETV6-ABL1), t(9,22) (q34;q11) (BCR-ABL1), t(10;11) (p12;q23) (MLL-MLLT10), t(11;17) (q23;q21) (MLL-MLLT6), t(11;17) (q23;q21) (ZBTB16RARA), $\quad t(11 ; 19) \quad$ (q23;p13.1) (MLL-ELL), $\quad t(11 ; 19)$ (q23;p13.3) (MLL-MLLT1), t(12;21) (p13;q22) (ETV6RUNX1), $\quad t(12 ; 22) \quad(p 13 ; q 11) \quad$ (ETV6-MN1), $t(15 ; 17)$ (q24;q21) (PML-RARA), inv(16) (p13;q22) (CBFBMYH11), t(16;21) (p11;q22) (FUS-ERG), t(17;19) (q22;p13) (TCF3-HLF), and $t(X ; 11)(q 13 ; q 23)(M L L-F O X O 4)^{17}$.

Only $20 \%$ of $B$-lineage leukemia and $60 \%$ of myeloid leukemia have common translocations ${ }^{18}$. However, more than 200 aberrations associated with this group of diseases are being explored through massive sequencing, real-time quantitative reverse transcription PCR (RT-qPCR), and digital PCR strategies, although they are only available for research. Notably, no other prognostic factor has been described with such a high significance as the ultrasensitive detection of MRD for AL through high-resolution technological systems. In addition, sensitivity is a highly relevant subject that involves technological aspects, reproducible protocols, systematized analysis strategies, and high technical resolution power. We describe the main benefits of several technologies applied to the diagnosis and evaluation of residual leukemia. 


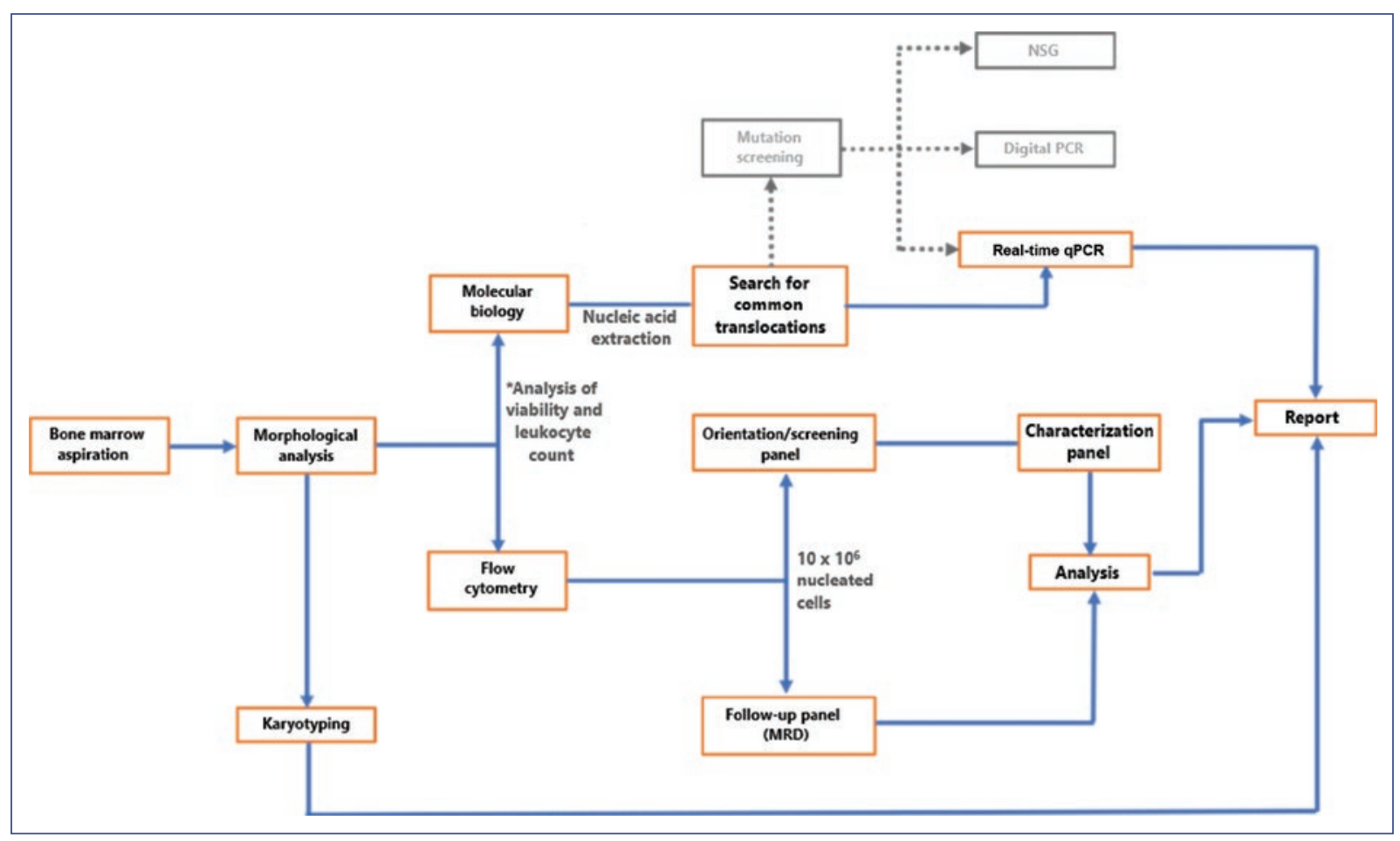

Figure 1. Workflow diagram for the comprehensive diagnosis of acute leukemia. According to the World Health Organization recommendations, leukemia diagnosis should be made from bone marrow aspirates, although peripheral blood smears can be used in particular situations. Collectively, morphological analysis, karyotyping, immunophenotyping, and molecular testing for the presence of genetic aberrations outline the comprehensive diagnosis.

\section{MRD and its prognostic value}

Once the diagnosis is established, the next step is to monitor the disease and the effectiveness through the detection of MRD. Several studies have emphasized the usefulness of monitoring tumor burden throughout treatment. Depending on the protocol, MRD can be determined on days $14,21,28,33$, or up to 78 days after treatment. The first attempts to monitor the reduction of malignant cells were carried out by observing histology slides and conventional staining. The introduction of terminal deoxynucleotidyl transferase (TdT) detection by fluorescence microscopy was of limited utility compared to first-generation flow cytometry (with two or three colors and high instrumental speed). The next challenge was distinguishing abnormal from normal developing clones after chemotherapy (hematogones), so more colors/markers were needed. The advent of modern cytometers allows gathering up to 6-8 markers in single staining, increasing the resolution power, and studying the co-expression of several molecules. Although classical microscopic techniques are still performed, MRD by molecular or cytometry techniques can redefine risk groups in complete morphological remissions ${ }^{19}$.

High sensitive molecular techniques have changed clinical outcomes, as documented by several controlled clinical trials demonstrating the superior prognostic value of MRD compared with leukocyte count, age, genotype, and early steroid response ${ }^{20}$. The purpose of MRD detection is to distinguish patients who respond well to therapy from those who require re-intensification, thus reducing high doses of chemotherapy in those patients at low risk, and recognizing patients who presumably have a low risk of relapse ${ }^{21}$. As previously mentioned, the prognostic value of MRD (currently determined by cytometry or RT-qPCR) is accepted as the most important factor in the clinical management of the disease due to a high correlation with the risk of early relapse ${ }^{22,23}$. Immunophenotyping at diagnosis is desirable but not necessary when following MRD. Innovative approaches used for tracking clones in B-ALL will be further discussed. However, such panels are not helpful for T-ALL and less so for myeloid origin leukemia, in which the recognition of the affected lineage at disease onset is essential for the appropriate 


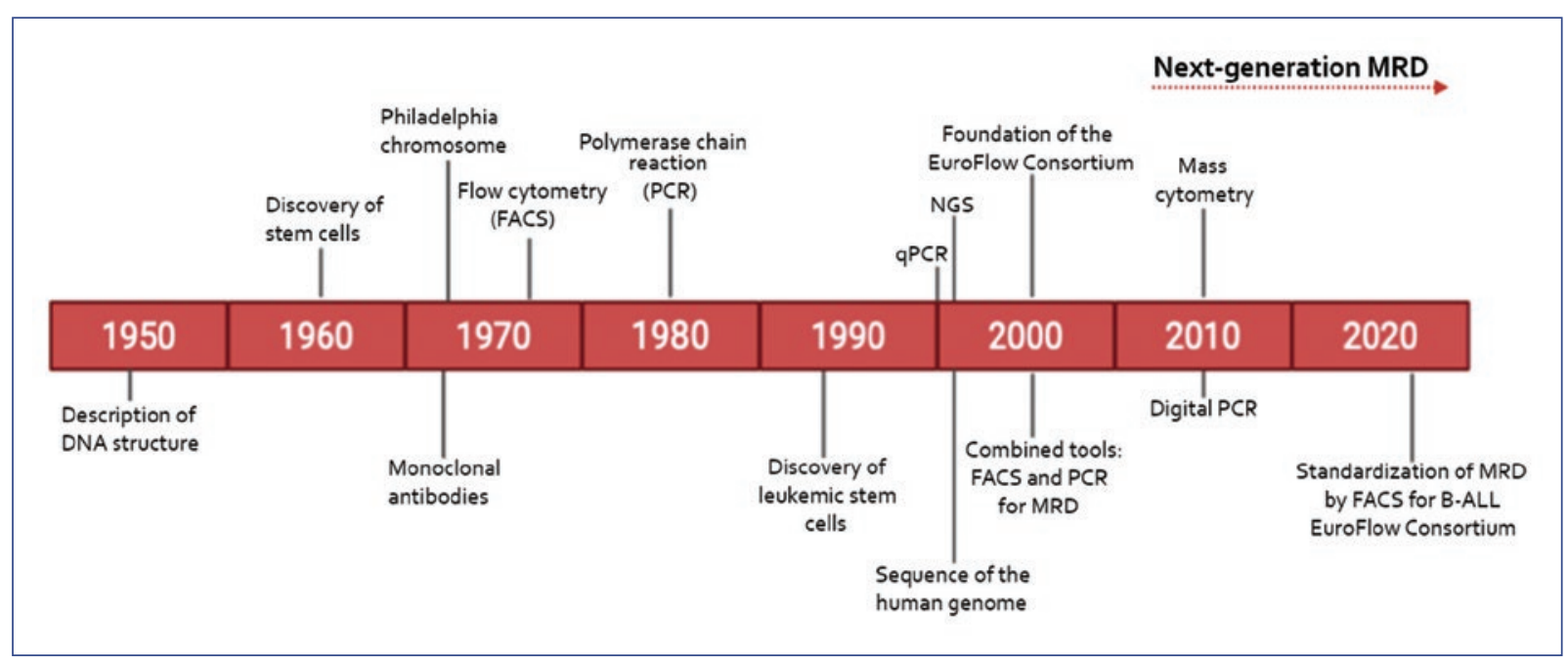

Figure 2. Timeline of relevant discoveries for the biological characterization of leukemia. Today's technology has been tangible thanks to fundamental discoveries that allowed the birth of modern molecular biology and the consideration of leukemic stem cells as the functional origin of these diseases and, therefore, as a target for treatment.

choice of MRD markers. Some case reports describe leukemic reemergence with lineage changes, possibly due to leukemic subclone's selection or the emergence of new clones during relapse ${ }^{24}$. Therefore, cytometry strategies should be sufficiently sensitive and phenotypically broad to identify re-emerging clones not associated with the lineage of origin.

Interestingly, MRD is also crucial in the prognosis of patients undergoing stem cell and hematopoietic progenitor transplantation, in whom MRD+ is often associated with unfavorable outcomes ${ }^{25}$.

Unfortunately, not all laboratories can determine MRD, as this does not depend on infrastructure but analysis and interpretation based on intensive training and in-depth knowledge of genotypic and phenotypic changes due to chemotherapy and pathways of differentiation of normal and malignant clones, among other biological aspects of the disease.

\section{Technology applied to the diagnosis and monitoring of hematological neoplasms}

The description of the double helix chain in the 1950s based on crystallographic studies by Rosalind Franklin was undoubtedly one of the most important discoveries for modern molecular biology. However, in the early 1960s, James Till and Ernest McCulloch demonstrated for the first time that bone marrow contained cells capable of regenerating blood in mice subjected to lethal doses of radiation. The hematopoietic system has been a gateway to several paradigms in medicine, as it has allowed various discoveries such as the description of the first cancer-associated translocation, the Philadelphia chromosome (by Janet Rowley). Later, this translocation led to discovering the first targeted therapy using inhibitors of the tyrosine kinase activity of the protein resulting from the fusion BCR-ABL and, of course, the discovery of cancer stem cells.

Undoubtedly, the development of monoclonal antibodies by Milstein and Köhler (1975) and the invention of flow cytometry made it possible to profile the immunophenotype of primitive cell populations and purify them through cell sorting. The development of these new tools prompted John Dick, who described a population parallel to that of normal stem cells capable of initiating leukemia. Research has expanded the knowledge of normal and pathological protein expression at the cellular level. The creation of consortia such as EuroFlow has allowed establishing the AL cell classification and detecting residual clones after chemotherapy.

The ability to amplify a specific region of the genome through PCR in the mid-1980s and, later, the ability to quantify the number of copies in real-time made it possible to measure, for the first time, the success of chemotherapy with molecular platforms (Fig. 2). Since then, and thanks to the human genome project, molecular tools such as massive NGS have made it possible to identify specific regions associated with cancer and new mutations, particularly those associated with leukemia. However, a combination of cellular and 
molecular strategies is recommended for the management of $M^{2} D^{18}$. Future technologies such as mass cytometry and other cytomics and molecular tools will allow highly sensitive detection of potentially MRD relapse-causing populations in the next generation.

\section{Multiparametric flow cytometry}

In daily practice, morphologic observations are usually confirmed by immunophenotyping. Although lymphoid blasts are usually distinguished from myeloid blasts, it is impossible to identify B or T lymphocyte blasts by simple colorimetric staining. Immunophenotyping is a highly specialized technique that uses flow cytometry to detect different fluorescent signals chemically coupled to antibodies that bind antigens with high specificity. As these antigens are usually membrane or cytoplasmic molecules, they can be detected simultaneously, if present in cells, according to the flow cytometer's optical configuration. At present, immunophenotyping is based on panels of 6-8 colors (or more), translating into the detection of multiple fluorescences associated with different cell markers. At least in commercial panels, this information enables identifying the presence/absence of several key parameters for the classification of the most relevant hematopoietic lineages. Validated in vitro diagnostic (IVD) antibody panels are available commercially to confirm the clinical suspicion of AL through a cytometry approach. The EuroFlow ${ }^{\top \mathrm{M}}$ Consortium has worked multicentrically to develop an intelligent combination screening tool that searches for eight specific markers of the $\mathrm{B}, \mathrm{T}$, and myeloid lineages, as well as molecules of hematological immaturity (Table 1). A correct analysis of such a guidance tube allows identifying $A L$ of $B$, $\mathrm{T}$, and myeloid lineage. Details on the aberrant expression of other molecules, identification of mixed phenotypes, and other markers of prognostic value are explored by adding other tubes with new antibody combinations.

The detection sensitivity for most commercially available flow cytometers is $0.01-0.001 \%\left(1 \times 10^{-4}-1 \times 10^{-5}\right)$, although the latter is not usually achieved. As the number of cells per sample is not always abundant, the acquisition of multiple tubes reduces the number of cells available for analysis. Therefore, the lower tubes acquired, the higher the number of markers involved (depending on the number of detectors of the equipment), and the higher the number of cells acquired, the higher the resolution capacity. Analysis software such as Infinicyt ${ }^{\mathrm{TM}}$ allows the fusion of tubes
Table 1. Antigens of the Euroflow ${ }^{\mathrm{TM}}$ panel ALOT (acute lymphoblastic orientation tube)

\begin{tabular}{|l|l|}
\hline Antigen & Cells expressing the antigen \\
\hline CD45 & Leukocytes \\
\hline CD34 & Stem cells and hematopoietic progenitors \\
\hline CD19 & B Lineage \\
\hline CyCD79a & \\
\hline smCD3 & T Lineage \\
\hline CyCD3 & \\
\hline CD7 & \\
\hline CyMP0 & Myeloid \\
\hline
\end{tabular}

from four markers-known as the backbone-and automatically calculates cell populations ${ }^{26}$. Achieving a high number of cells in samples obtained after chemotherapy is challenging because the collection of mononuclear cells may compromise the recovery of leukemic clones to the point of loss. Therefore, staining of the entire sample before bulk lysis is strongly recommended ${ }^{19}$.

\section{Next-generation flow cytometry}

Undoubtedly, one of the fundamental laboratory challenges for leukemia is the detection of MRD. Some protocols define MRD prognostic value as early as day 15 , while others at day 28 or 33 . The real challenge lies in finding residual clones with alterations in the normal maturation pattern or the presence of aberrant markers. Either scenario requires training in detecting normal cell maturation to identify pathological clones and markers to discern between developing cells and those that have survived chemotherapy.

As mentioned previously, flow cytometry can reach the detection limit of $1 \times 10^{-5}$. However, to achieve maximum reliability, it is necessary to acquire an optimal number of cells (at least 5 million). There is no consensus on the minimum number of cells to define a cluster as a cell population; however, it is suggested to be between 10 and 50 events $^{27}$. Another recommendation is to use specialized software for analysis, especially in MRD studies, where many nucleated cells (up to 10 million) have been acquired to search for residual clones.

Another challenge is the markers' stability during treatment, as some disappear or are induced after 
Table 2. Patients with positive blast populations for CD73, CD86, CD44, and CD304 antigens in various international studies

\begin{tabular}{|l|c|c|c|c|c|}
\hline \multirow{2}{*}{ Antigen } & \multicolumn{5}{|c|}{ Percentage (\%) of patients in each study } \\
\cline { 2 - 6 } & Meyerson et al. ${ }^{30}$ & Coustan-Smith et al. ${ }^{4}$ & Solly et al. ${ }^{31}$ & Sędek et al. ${ }^{28}$ & Nagant et al. ${ }^{44}$ \\
\hline CD73 & 76.7 & 54.5 & - & 66 & - \\
\hline CD81 & - & - & - & - & 100 \\
\hline CD86 & 56.7 & 46.7 & - & 58 & - \\
\hline CD44 & 50 & 53.5 & - & - & - \\
\hline CD24 & 20 & 11.5 & - & - & - \\
\hline CD304 & - & 71 & 48 & 59 & - \\
\hline CD123 & - & - & - & - & 34 \\
\hline CD58 & - & - & - & - & 90 \\
\hline
\end{tabular}

rounds of chemotherapy ${ }^{28}$. Several studies have aimed to find the best combination of markers for disease tracing, especially in B-lymphoid origin leukemia, for which panels include, at least, the detection of CD19, CD79a, CD34, CD45, and CD3 antigens. Some options for monitoring MRD are further discussed (Table 2).

\section{CD73}

CD73 is an ectonucleotidase that produces adenosine (ADO) from extracellular ADO triphosphate (ATP). Under physiological conditions, it is expressed on the surface of some $B$ cells and subpopulations of $T$ and NK cells ${ }^{29}$. The role of CD73 is to create a suppressive environment after hydrolysis of extracellular ATP (damage signal) and reduce inflammation by generating ADO, a molecule with immunosuppressive potential. In a multicenter study, CD73 was shown to be aberrantly highly expressed on B-lineage blasts compared to its normal counterpart in $66 \%$ of the enrolled patients and was stable 15 days after initiation of treatment ${ }^{28}$. More recent reports have documented that $\mathrm{CD} 73$ has a greater tendency to increase significantly after treatment ${ }^{29}$.

\section{CD304}

CD304 (also called neuropilin 1) functions as a co-receptor for the vascular endothelial growth factor and semaphorin. It is expressed on plasmacytoid dendritic cells and some monocyte populations under physiological conditions, although normal pre-B populations usually express discrete levels ${ }^{30}$. Based on expression data and subsequently corroborating the findings by flow cytometry, Coustan-Smith et al. demonstrated the role of CD304 as a valuable molecule for monitoring MRD by comparing purified leukemic blasts with their normal counterpart ${ }^{4}$. B-ALL leukemic blasts significantly overexpress CD304. Its expression correlates with the presence of $t(12 ; 21)$ ETV6-RUNX1, which originates the TEL/AM1 fusion, and is inversely related to rearrangements in the MLL gene $e^{4,28,31}$. In combination with CD9, it could be helpful for the prediction of $t(12 ; 21)$ translocation ${ }^{32}$.

Interestingly, CD73 showed a positive correlation with CD304 expression, for which their combination results in a powerful strategy to identify residual clones during B-ALL (Fig. 3).

\section{CD86}

Under physiological conditions, B cells express basal levels of CD86. However, after activation, its expression increases considerably. Besides, plasma cells maintain abundant expression. CD86 may be expressed on the surface of leukemic blasts in some patients with B-ALL, but there is no apparent correlation with any particular immunophenotype (pro-B or pre-B) or genetic subgroup. Rearrangements of the MLL gene and the BCR$A B L 1$ fusion protein have been associated with positivity to the marker. However, due to the low frequency of these subgroups, it is challenging to generate significant statistics ${ }^{28}$. The trend has been confirmed in at least half of the patients with B-ALL in whom CD86 expression has been explored, but few studies have addressed its potential use for MRD follow-up ${ }^{4,28}$. 

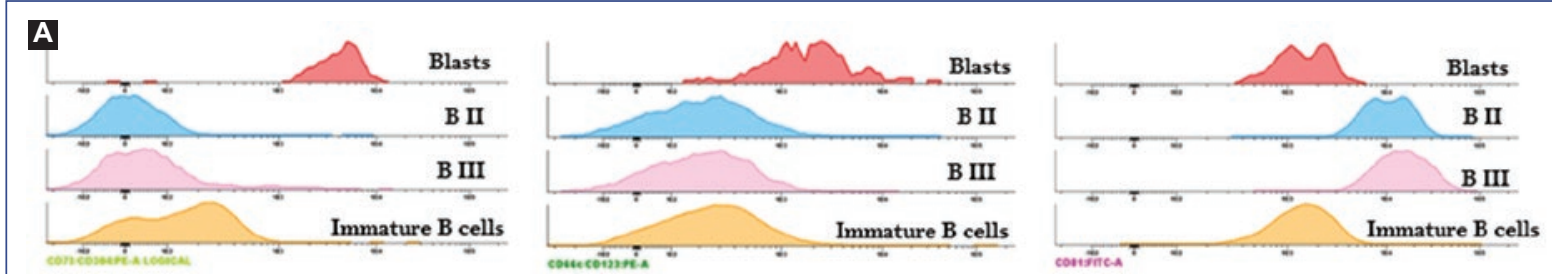

B
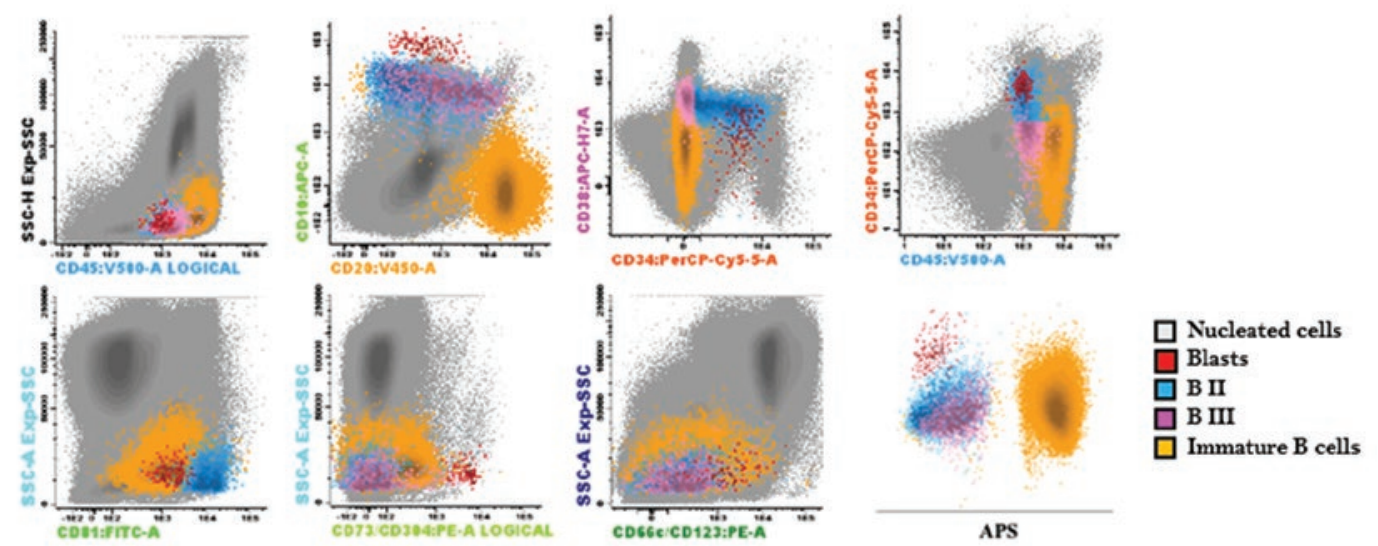

Figure 3. Differential expression of some markers useful for monitoring minimal/measurable residual disease. A. Differential expression of CD73/CD304 (left), CD66c/CD123 (center), and CD81 (right) in populations of residual B lymphoid blasts (CD45low CD34+ CD10+ CD20low), Bll precursors (CD45low CD34+ CD38+ CD10+ CD20low/int), BIII (CD34- CD38+ CD10+ CD20low/int) and immature B cells (CD45hi CD34- CD38- CD10- CD20+). B. Dot plots of the different populations described above, the blasts population represents $0.0018 \%$ of the nucleated cells. APS: automatic population separator. Analysis performed in Infinicyt 2.0, Nereida Méndez.

\section{CD58}

Lymphocyte function-associated antigen 3 (LFA-3) or CD58 is expressed on the surface of antigen-presenting cells, especially macrophages. In most cases (> $90 \%$ ), it is present in leukemic blasts and is stable in the treatment phase, making it a good candidate for monitoring $\mathrm{MRD}^{33}$. In a study that included 69 patients, CD58 helped detect ten patients with MRD (+) confirmed by $\mathrm{PCR}^{34}$. Despite being identified as one of the most outstanding molecules as MRD markers, other studies have shown that its implementation generates limited information for detecting remnant clones ${ }^{27,34}$.

\section{CD66c}

This glycoprotein participates in cell adhesion and is expressed on the surface of cells of myeloid origin under normal conditions; however, it is absent in non-pathologic lymphocyte populations. In B-ALL, this molecule is aberrantly expressed on the surface of blasts, especially in cases with the $t(9 ; 22)$ translocation that originates the BCR-ABL1 fusion protein ${ }^{35,36}$.
Molecular subgroups with hyperdiploidy frequently express the CD66C antigen ${ }^{28,37}$. Recently, the EuroFlow ${ }^{\top \mathrm{TM}}$ Consortium observed that the combination of $\mathrm{CD} 66 \mathrm{c}$ with $\mathrm{CD} 123$ provided valuable information (Fig. $3 \mathrm{~A}$ and $\mathrm{B}$ ) by the separation obtained of malignant populations ${ }^{27}$.

\section{CD123}

Myeloid progenitors, plasmacytoid dendritic cells, and basophils express the alpha chain of the IL-3 receptor (IL-3), CD123, whose signaling is involved in differentiation, proliferation, and survival processes. Experimental data confirm that CD123 is overexpressed on the surface of B-ALL and AML leukemic blasts; however, it is underrepresented in T-type leukemias ${ }^{38}$. Interestingly, the hyperdiploid genotype is associated with high CD123 expression. Therefore, in combination with CD86 and CD200, it could potentially identify this molecular subgroup ${ }^{4,39}$. In addition to being expressed in lymphoid cells, this molecule is currently used as a therapeutic target for immunological therapy since it is 
also explicitly expressed in leukemic stem cells of $\mathrm{AML}^{40}$.

\section{CD44}

CD44 is expressed in the cell membrane of various tissues and participates in cell adhesion and migration. During the early development of T cells, CD44 plays an essential role during the arrival of progenitors from the bone marrow to the thymus. Although its role seems more significant for T-ALL, B-lineage blasts express CD44 in almost $53.5 \%$ of cases $^{4,30}$. Furthermore, its expression has been confirmed in AML blasts ${ }^{41}$. CD44 is one of the most studied tumor markers; its combination with CD24 has helped identify tumor stem cells in various solid tumors. Notably, BCR$\mathrm{ABL}$ patients directly correlate with CD44 expression $^{42}$.

\section{CD81}

CD81 belongs to a family of proteins known as tetraspanins. Under physiological conditions, CD81 is expressed in the surface of mature $B$ and $T$ cells, for which it is considered a molecule associated with lymphocyte maturation. Therefore, CD81 may be detectable from the early stages of lymphopoiesis, and its density increases as populations mature ${ }^{43-45}$. The absence of CD81 expression and positivity to other markers, such as CD58, marks suspiciously malignant populations ${ }^{44}$. Thus, the combination allows identifying residual blastic clones from developing normal progenitors (hematogones) (Fig. 3).

\section{Mass cytometry}

This technology merges two well-known approaches: flow cytometry and mass spectrometry. This combination generates proteomic analyses at a single-cell level. In practical terms, mass cytometry or cytometry by time-of-flight requires a suspension of cells "labeled" with antibodies coupled to pure elements (initially metals) instead of fluorochromes as in traditional flow cytometry. In this technique, cells are nebulized, and metals are associated with the cells and detected by mass spectrometry due to specific binding with the antibodies. Therefore, more than 40 proteins can be analyzed simultaneously without the need for compensation since each element is unique and identifiable by its atomic mass. Although this tool is mainly used in research, the number of parameters exceeds those achieved by the most equipped traditional cytometer. In the future, this technology could be applied to detect MRD with a much higher resolution $^{46,47}$. However, one of the disadvantages is that the sample has to be disintegrated, so cells cannot be recovered for further studies. With the recent emergence of spectral flow cytometry, it is possible to investigate 48 colors/markers by analyzing the entire emission spectrum of each fluorochrome that is part of the panel rather than the peak emission, as occurs with conventional flow cytometry. Moreover, the development of cell purification kits based on this detection strategy is underway, as well as the detection of messenger RNAs useful for the most common genetic abnormalities (in combination with classical immunophenotyping). In the coming years, the implementation of specific oligonucleotide-conjugated antibodies will provide the possibility of single-cell transcriptomics based on traditional flow cytometry ${ }^{48}$.

\section{Molecular biology in MRD}

Before cytometry, MRD was traditionally measured through RT-PCR, detecting fusion products generated by translocations, although limited. With the development of digital PCR, a high precision quantification is possible now. Furthermore, the measurement of $V(D) J$ rearrangement products allows identifying the immunological reconstitution of patients. However, as only one technique has been mainly used historically, few studies were initially consistent when combining techniques, possibly due to the lack of standardization ${ }^{49}$. Because of their predictive value, numerous technological and scientific efforts are underway to improve methods and innovate to identify clones that resist traditional therapy. Thus, results on massive sequencing techniques for MRD determination suggest a higher predictive accuracy for predicting relapse compared with other strategies $^{50}$.

Recently, Waanders et al. demonstrated that relapse clones originated from subclones existing at diagnosis with variable abundance and identified some candidate genes that may undergo additional mutations such as NCOR2, USH2A, and NT5C2, evidenced by digital PCR before clinical relapse ${ }^{51}$. Undoubtedly, MRD detection is aided by cutting-edge technology but requires rapid and standardized techniques ${ }^{52}$. For lowand middle-income countries, the cost of such assays should be affordable for patients or public health services. 


\section{MRD in myeloid leukemia}

Detection of gene fusion products by RT-qPCR is one of the most commonly used strategies in AML alongside flow cytometry. Since approximately $60 \%$ of myeloid leukemia belong to a molecular group, their traceability is facilitated by this method during treatment. At present, NGS's advantage is that it allows parallel information on the associated mutations and the detection of fusion products for these disorders ${ }^{53}$. Because of the high phenotypic heterogeneity within the same disease, there has been a significant delay in developing guidelines addressing all the characteristics. ALL protocols have been adapted to search residual cells through flow cytometry, but the results have differed considerably ${ }^{54}$. One of the biggest challenges for the cytometrist is distinguishing malignant clones from normal myeloid reconstitution. Despite the description of leukemic stem cells, only a few studies have followed these cells during MRD. However, given that the immunophenotype of CTLs can be variable between patients, proposing a panel that allows generalization is complex ${ }^{10}$. The search for stemness in AML during MRD and LICs in acute lymphoblastic leukemia would be handy.

\section{MRD in the cerebrospinal fluid}

Only about $30 \%$ of relapses occur in the central nervous system (CNS), and the detection of leukemic clones in the cerebrospinal fluid (CSF) at diagnosis occurs in $<15 \%$ of patients. These results are associated with a worse prognosis due to an increased risk of relapse ${ }^{55}$. The mechanisms underlying CNS colonization are not well understood, but experimental investigations indicate that blasts can cross the blood-brain barrier. Alternatively, potential "seeding" of blasts in the CNS during sample collection or prophylaxis protocols has been suggested ${ }^{56}$. Furthermore, the use of immunodeficient animal models has highlighted the determinant role of the antitumor surveillance system and the migratory capacity of leukemic populations in relapsing leukemia, distinguishable by a high expression of cortactin $^{57}$.

Malignant blasts in the CSF are traditionally detected by cytology after concentrating the sample (cytospin). Moreover, blasts can be evaluated by flow cytometry using strategic combinations, including CD45, CD19, CD20, CD4, CD8, CD56, Ig lambda, Ig kappa, CD3, $\mathrm{CD} 14$, and $\mathrm{CD} 38$ antigens ${ }^{16}$, to identify the infiltrate's cellular composition. A study of 673 patients showed that the relapse incidence at 4 years was higher in those where leukemic blasts were detected in the CSF by flow cytometry. Despite the superior advantages of flow cytometry over cytology, there is no consensus for leukemia diagnosis in the CSF, although several algorithms have already been thoroughly reviewed ${ }^{58}$. Other studies rely on molecular techniques for the detection of MRD in the CSF through PCR ${ }^{59}$. Regardless of the above, the biggest challenge is the correct preservation of the cellular material from the CSF, possibly implementing cell stabilizers for flow cytometry or nucleic acids. However, the low-volume sample cutting-edge techniques discussed here are also being explored for such frontier approaches ${ }^{60}$.

\section{Future perspectives and challenges}

MRD detection represents a challenge from several perspectives, including low cell number in aspirates, lack of smart marker configuration, need for cytometers with more than five colors, the involvement of highly trained analysts, and specialized software, among others. Sometimes, diagnostic immunophenotyping is not available, or the laboratories' lack of systematization makes it challenging to follow-up residual clones. An advantage of hematological disorders with common molecular signatures is that such translocations can be monitored with high sensitivity by RT-qPCR. Moreover, mass cytometry or massive sequencing proposals will be explored in the coming years and addressed in pilot studies before being transferred to the clinic as routine protocols in our country. However, with the advancement of technology and the collaboration of different reference centers, most MRD measurement protocols are being standardized by conventional flow cytometry, which will provide greater accuracy and robustness. In Mexico, several initiatives for the consensus of markers and protocols for cytometry diagnosis will reduce the number of cases inaccurately diagnosed and evaluate treatment response and the increase in the overall survival of pediatric patients.

\section{Ethical disclosures}

Protection of human and animal subjects. The authors declare that no experiments were performed on humans or animals for this study.

Confidentiality of data. The authors declare that they have followed the protocols of their work center on patient data publication. 
Right to privacy and informed consent. The authors declare that no patient data appear in this article.

\section{Conflicts of interest}

The authors declare no conflict of interest.

\section{Funding}

The research of the Laboratorio de Oncoinmunología CIBIOR is supported by the Programa Nacional Estratégico de Salud del Consejo Nacional de Ciencia y Tecnología CONACYT (PRONAll Leucemia Infantil 302994) and by the Coordinación de Investigación en Salud del IMSS (FIS/IMSS/PROT/G18/1828).

\section{Acknowledgments}

The authors acknowledge the collaboration of the members of the Laboratorio Juárez S.A. de C.V. and the Hospital Universitario, Universidad Autónoma de Nuevo León, Monterrey, Nuevo León, Mexico.

\section{References}

1. Gómez-Almaguer D, Marcos-Ramírez ER, Montaño-Figueroa $E H$, Ruiz-Argüelles GJ, Best-Aguilera CR, López-Sánchez MDC, et al. Acute leukemia characteristics are different around the world: the Mexican perspective. Clin Lymphoma Myeloma Leuk. 2017;17:46-51.

2. Force, LM, Abdollahpour I, Advani SM, Agius D, Ahmadian E, Alahdab F, et al. The global burden of childhood and adolescent cancer in 2017: an analysis of the Global Burden of Disease Study 2017. Lancet Oncol. 2019;20:1211-25.

3. Balandrán, JC, Vadillo E, Dozal D, Reyes-López A, Sandoval-Cabrera A Laffont-Ortiz MD, et al. Analysis of normal hematopoietic stem and progenitor cell contents in childhood acute leukemia bone marrow. Arch Med Res. 2016;47:629-43.

4. Coustan-Smith E, Song G, Clark C, Key L, Liu P, Mehrpooya M, et al. New markers for minimal residual disease detection in acute lymphoblastic leukemia. Blood. 2011;117:6267-76.

5. Mirkowska P, Hofmann A, Sedek L, Slamova L, Mejstrikova E, Szczepanski $T$, et al. Leukemia surfaceome analysis reveals new disease-associated features. Blood. 2013;121:e149-59.

6. Lapidot T, Sirard C, Vormoor J, Murdoch B, Hoang T, Caceres-Cortes J, et al. A cell initiating human acute myeloid leukaemia after transplantation into SCID mice. Nature. 1994;367:645-8.

7. le Viseur C, Hotfilder M, Bomken S, Wilson K, Röttgers S, Schrauder A, et al. In childhood acute lymphoblastic leukemia, blasts at different stages of immunophenotypic maturation have stem cell properties. Cancer Cell. 2008; $14: 47-58$.

8. Ebinger S, Özdemir EZ, Ziegenhain C, Tiedt S, Castro Alves C Grunert M, et al. Characterization of rare, dormant, and therapy-resistant cells in acute lymphoblastic leukemia. Cancer Cell. 2016;30:849-62.

9. Elder A, Bomken S, Wilson I, Blair HJ, Cockell S, Ponthan F, et al. Abundant and equipotent founder cells establish and maintain acute lymphoblastic leukaemia. Leukemia. 2017;31:2577-86.

10. Terwijn M, Zeijlemaker W, Kelder A, Rutten AP, Snel AN, Scholten WJ, et al. Leukemic stem cell frequency: a strong biomarker for clinical outcome in acute myeloid leukemia. PLoS One 2014;9:e107587.

11. Purizaca J, Contreras-Quiroz A, Dorantes-Acosta E, Vadillo E, Arriaga-Pizano L, Fuentes-Figueroa $S$, et al. Lymphoid progenitor cells from childhood acute lymphoblastic leukemia are functionally deficient and express high levels of the transcriptional repressor Gfi-1. Clin Dev Immunol. 2013;2013:349067.

12. Balandrán JC, Purizaca J, Enciso J, DozaL D, Sandoval A, Jiménez-Hernández E, et al. Pro-inflammatory-related loss of CXCL12 niche promotes acute lymphoblastic leukemic progression at the expense of normal lymphopoiesis. Front Immunol. 2016;7:666.
13. Vilchis-Ordoñez A, Contreras-Quiroz A, Vadillo E, Dorantes-Acosta E, Reyes-López A, Quintela-Nuñez del Prado HM, et al. Bone marrow cells in acute lymphoblastic leukemia create a proinflammatory microenvironment influencing normal hematopoietic differentiation fates. Biomed Res. Int 2015;2015:386165.

14. Kumar B, Garcia M, Weng L, Jung X, Murakami JL, Hu X, et al. Acute myeloid leukemia transforms the bone marrow niche into a leukemia-permissive microenvironment through exosome secretion. Leukemia. 2018;32:575-87.

15. Arriaga-Pizano L, Ramírez-Ramírez D, Prieto-Chávez J, Pelayo R, Ruiz-Argüelles A. Reporte de la Primera Reunión Nacional de Consenso para la Inmunofenotipificación de Leucemias Agudas. Gac Med Mex. 2019;155:20-9.

16. Van Dongen JJ, Lhermitte L, Böttcher S, Almeida J, van der Velden VH, Flores-Montero J, et al. EuroFlow antibody panels for standardized n-dimensional flow cytometric immunophenotyping of normal, reactive and malignant leukocytes. Leukemia. 2012;26:1908-75.

17. Meyer-Monard S, Parlier V, Passweg J, Mühlematter D, Hess U, Bargetzi M, et al. Combination of broad molecular screening and cytogenetic analysis for genetic risk assignment and diagnosis in patients with acute leukemia. Leukemia. 2006;20:247-53.

18. Neale, GAM, Coustan-Smith E, Stow $P, P a n Q$, Chen $X, P u i ~ C H$, et al. Comparative analysis of flow cytometry and polymerase chain reaction for the detection of minimal residual disease in childhood acute lymphoblastic leukemia. Leukemia. 2014;18:934-8.

19. Paietta $\mathrm{E}$. Assessing minimal residual disease (MRD) in leukemia: a changing definition and concept? Bone Marrow Transplant. 2002;29:459-65.

20. Conter V, Bartram CR, Valsecchi MG, Schrauder A, Panzer-Grümayer R, Möricke $A$, et al. Molecular response to treatment redefines all prognostic factors in children and adolescents with B-cell precursor acute lymphoblastic leukemia: results in 3184 patients of the AIEOP-BFMALL 2000 study. Blood. 2010;115:3206-14.

21. Vora A, Goulden N, Wade R, Mitchell C, Hancock J, Hough R, et al. Treatment reduction for children and young adults with low-risk acute lymphoblastic leukaemia defined by minimal residual disease (UKALL 2003): a randomised controlled trial. Lancet Oncol. 2013;14:199-209.

22. Starza ID, Chiaretti S, De Propris MS, Elia L, Cavalli M, De Novi LA, et al. Minimal residual disease in acute lymphoblastic leukemia: technical and clinical advances. Front Oncol. 2019;9:726.

23. Pui Ch, Pei D, Raimondi SC, Coustan-Smith E, Jeha S, Cheng C, et al. Clinical impact of minimal residual disease in children with different subtypes of acute lymphoblastic leukemia treated with response-adapted therapy. Leukemia. 2017;31:333-9.

24. Dorantes-Acosta E, Pelayo R. Lineage switching in acute leukemias: a consequence of stem cell plasticity? Bone Marrow Res. 2012;2012:406796.

25. Sramkova L, Muzikova K, Fronkova E, Krejci O, Sedlacek P Formankova $R$, et al. Detectable minimal residual disease before allogeneic hematopoietic stem cell transplantation predicts extremely poor prognosis in children with acute lymphoblastic leukemia. Pediatr Blood Cancer. 2007;48:93-100.

26. Pedreira CE, Costa ES, Lecrevisse Q, van Dongen JJM, Orfao A, EuroFlow Consortium. Overview of clinical flow cytometry data analysis: recent advances and future challenges. Trends Biotechnol. 2013;31:415-25.

27. Theunissen $P$, Mejstrikova $E$, Sedek $L$, van der Sluijs-Gelling AJ, Gaipa G, Bartels M, et al. Standardized flow cytometry for highly sensitive MRD measurements in B-cell acute lymphoblastic leukemia. Blood 2017; 129:347-57.

28. Sędek $\measuredangle$, Theunissen $P$, Sobral da Costa $E$, van der Sluijs-Gelling $A$, Mejstrikova E, Gaipa G, et al. Differential expression of CD73, CD86, and CD304 in normal vs. leukemic B-cell precursors and their utility as stable minimal residual disease markers in childhood B-cell precursor acute lymphoblastic leukemia. J Immunol Methods. 2019;475:112429.

29. Allard B, Longhi MS, Robson SC, Stagg J. The ectonucleotidases CD39 and CD73: novel checkpoint inhibitor targets. Immunol Rev. 2017;276:121-44.

30. Meyerson HJ, Blidaru G, Edinger A, Osei E, Schweitzer K, Fu P, et al. NRP-1/CD304 expression in acute leukemia: a potential marker for minimal residual disease detection in precursor B-cell acute lymphoblastic leukemia. Am J Clin Pathol. 2012;137:39-50.

31. Solly F, Angelot F, Garand R, Ferrand C, Seillès E, Schillinger F, et al. CD304 is preferentially expressed on a subset of B-lineage acute lymphoblastic leukemia and represents a novel marker for minimal residual disease detection by flow cytometry. Cytometry A. 2012;81:17-24.

32. Gandemer V, Aubry M, Roussel M, Rio AG, de Tayrac M, Vallee A, et al. CD9 expression can be used to predict childhood TEL/AML1-positive acute lymphoblastic leukemia: proposal for an accelerated diagnostic flowchart. Leuk Res. 2010;34:430-7.

33. Veltroni M, De Zen L, Sanzari MC, Maglia O, Dworzak MN, Ratei R, et al. Expression of CD58 in normal, regenerating and leukemic bone marrow $B$ cells: implications for the detection of minimal residual disease in acute lymphocytic leukemia. Haematologica. 2003;88:1245-52.

34. Shaver AC, Greig BW, Mosse CA, Seegmiller AC. B-ALL minimal residual disease flow cytometry: an application of a novel method for optimization of a single-tube model. Am J Clin Pathol. 2015;143:716-24. 
35. Kiyokawa N, lijima K, Tomita O, Miharu M, Hasegawa D, Kobayashi K, et al. Significance of CD66c expression in childhood acute lymphoblastic leukemia. Leuk Res. 2014;38:42-8.

36. Kalina T, Vaskova M, Mejstrikova E, Madzo J, Trka J, Stary J, et al Myeloid antigens in childhood lymphoblastic leukemia: clinical data poin to regulation of $\mathrm{CD} 66 \mathrm{c}$ distinct from other myeloid antigens. BMC Cancer. 2005;5:38.

37. Cruz Rubio S, Lancheros A, Márquez Benitez Y, Mosquera Heredia M, Oliveros Barros J. Caracterización biológica del marcador CD66c y su importancia clínica en la leucemia linfoide aguda. Rev Cubana Hemato Inmunol Hemoter. 2018:34:1-12.

38. Bras AE, de Haas V, van Stigt A, Jongen-Lavrencic M, Beverloo HB, Te Marvelde JG, et al. CD123 expression levels in 846 acute leukemia patients based on standardized immunophenotyping. Cytometry B Clin Cytom. 2019;96:134-42.

39. Djokic M, Björklund E, Blennow E, Mazur J, Söderhäll S, Porwit A. Overexpression of $C D 123$ correlates with the hyperdiploid genotype in acute lymphoblastic leukemia. Haematologica. 2009:94:1016-9.

40. Jordan CT, Upchurch D, Szilvassy SJ, Guzman ML, Howard DS, Pettigrew AL, et al. The interleukin-3 receptor alpha chain is a unique marker for human acute myelogenous leukemia stems cells. Leukemia. 2000;14:1777-84.

41. Codeco Marques LVC, Pereira Noronha E, Gomes Andrade F, Dos Santos-Bueno FV, Mansur MB, Terra-Granado E, et al. CD44 expression profile varies according to maturational subtypes and molecular profiles of pediatric T-cell lymphoblastic leukemia. Front Oncol. 2018:8:488.

42. Tembhare PR, Ghogale S, Ghatwai N, Badrinath Y, Kunder N, Patkar NV et al. Evaluation of new markers for minimal residual disease monitoring in B-cell precursor acute lymphoblastic leukemia: CD73 and CD86 are the most relevant new markers to increase the efficacy of MRD 2016; 00B: 000-000. Cytometry B Clin Cytom. 2018;94:100-11.

43. Tsitsikov E, Harris MH, Silverman LB, Sallan SE, Weinberg OK. Role of CD81 and CD58 in minimal residual disease detection in pediatric B lymphoblastic leukemia. Int J Lab Hematol. 2018;40:343-51.

44. Nagant C, Casula D, Janssens A, Nguyen VTP, Cantinieaux B. Easy discrimination of hematogones from lymphoblasts in B-cell progenitor acute lymphoblastic leukemia patients using CD81/CD58 expression ratio. Int J Lab Hematol. 2018;40:734-9.

45. Chernysheva O, Grivtsova LY, Popa A, Tupitsyn N. B-Cell Precursors: Immunophenotypic Features in the Detection of Minimal Residual Disease in Acute Leukemia. In: Aribi M, editor. Normal and Malignant B-Cell. London: IntechOpen; 2019. Available from: https://www.intechopen.com/books/ normal-and-malignant-b-cell/b-cell-precursors-immunophenotypic-features-in-the-detection-of-minimal-residual-disease-in-acute-le.

46. Han L, Qiu P, Zeng Z, Jorgensen JL, Mak DH, Burks JK, et al. Single-cell mass cytometry reveals intracellular survival/proliferative signaling in FLT3-ITD-mutated AML stem/progenitor cells. Cytometry A 2015;87:346-56.

47. Behbehani GK, Samusik N, Bjornson ZB, Fantl WJ, Medeiros BC, Nolan GP. Mass cytometric functional profiling of acute myeloid leukemia defines cell-cycle and immunophenotypic properties that correlate with known responses to therapy. Cancer Discov. 2015;5:988-1003.
48. Martin J, Fan HC, Shum E. Oligo-conjugated antibodies (Ab-seq) and massively parallel single-cell sequencing reveal the high parameter correlation of protein and mRNA expression in individual immune cells. $J$ Immunol. 2018:200 Suppl 1:120.33.

49. Ryan J, Quinn F, Meunier A, Boublikova L, Crampe M, Tewari P, et al. Minimal residual disease detection in childhood acute lymphoblastic leukaemia patients at multiple time-points reveals high levels of concordance between molecular and immunophenotypic approaches. $\mathrm{Br} \mathrm{J}$ Haematol. 2009;144:107-15.

50. Kotrova M, Muzikova K, Mejstrikova E, Novakova $M$, Bakardjieva-Mihaylova V, Fiser K, et al. The predictive strength of next-generation sequencing MRD detection for relapse compared with current methods in childhood ALL. Blood. 2015;126:1045-7.

51. Waanders E, Gu Z, Dobson SM, Antić Z, Crawford JC, Ma X, et al. Mutational landscape and patterns of clonal evolution in relapsed pediatric acute lymphoblastic leukemia. Blood Cancer Discov. 2020;1:1-16.

52. Van Dongen JJ, Van Der Velden VH, Brüggemann M, Orfao A. Minimal residual disease diagnostics in acute lymphoblastic leukemia: need for sensitive, fast, and standardized technologies. Blood. 2015;125:3996-4009.

53. Grimwade D, Ivey A, Huntly BJP. Molecular landscape of acute myeloid leukemia in younger adults and its clinical relevance. Blood. 2016:127:29-41.

54. Coustan-Smith E, Ribeiro RC, Rubnitz JE, Razzouk BI, Pui CH, Pounds $\mathrm{S}$, et al. Clinical significance of residual disease during treatment in childhood acute myeloid leukaemia. Br J Haematol. 2003:123:243-52.

55. Thastrup M, Marquart HV, Levinsen M, Grell K, Abrahamsson J, Klug Albertsen B, et al. Flow cytometric detection of leukemic blasts in cerebrospinal fluid predicts risk of relapse in childhood acute lymphoblastic leukemia: a nordic society of pediatric hematology and oncology study. Leukemia. 2020;34:336-46.

56. Williams MT, Yousafzai YM, Elder A, Rehe K, Bomken S, Frishman-Levy L, et al. The ability to cross the blood-cerebrospinal fluid barrier is a generic property of acute lymphoblastic leukemia blasts. Blood. 2016;127:1998-2006.

57. Velázquez-Ávila M, Balandrán JC, Ramírez-Ramírez D, Velázquez-Ávila M, Sandoval A, Felipe-López A, et al. High cortactin expression in B-cell acute lymphoblastic leukemia is associated with increased transendothelial migration and bone marrow relapse. Leukemia. 2018;33:1337-48.

58. Crespo-Solis E, López-Karpovitch X, Higuera J, Vega-Ramos B. Diagnosis of acute leukemia in cerebrospinal fluid (CSF-Acute Leukemia). Curr Oncol Rep. 2012;14:369-78.

59. Biojone E, Queiróz RD, Valera ET, Odashima NS, Takayanagui OM, Viana MB, et al. Minimal residual disease in cerebrospinal fluid at diagnosis: a more intensive treatment protocol was able to eliminate the adverse prognosis in children with acute lymphoblastic leukemia. Leuk Lymphoma. 2012:53:89-95.

60. Bartram J, Goulden N, Wright G, Adams S, Brooks T, Edwards D, et al. High throughput sequencing in acute lymphoblastic leukemia reveals clonal architecture of central nervous system and bone marrow compartments. Haematologica. 2018;103:e110-4. 